\title{
Impact of a clinical pathway for relieving severe post-operative pain at a university hospital in South America
}

\author{
Adriana M. Cadavid-Puentes ${ }^{1}$, John S. Gonzalez-Avendano ${ }^{1,2^{*}}$, Juliana M. Mendoza' ${ }^{1}$, Marta I. Berrío', Nancy D. Gomez ${ }^{1}$, Ada M. Villalba1', \\ Daniel C. Aguirre-Acevedo ${ }^{3}$ and Fanny I. Diaz ${ }^{4}$ \\ *Correspondence: sebastiangonzalezmd@gmail.com \\ 'Faculty of Medicine, University of Antioquia, Medellin, Colombia. \\ ${ }^{2}$ Faculty of Pharmaceutical Chemistry, University of Antioquia, Medellin, Colombia. \\ ${ }^{3}$ Statistician-Epidemiologist, University of Antioquia, Medellin, Colombia. \\ ${ }^{4}$ Nurse, Pain Service, Hospital Universitario San Vicente Fundacion, Medellin, Colombia.
}

\begin{abstract}
Background: Many patients experience severe Post-Operative Pain (POP) worldwide despite current advances in pain management. The clinical pathway for pain management is a strategy that has shown positive results for relieving pain and other negative outcomes, such as cardiovascular and respiratory complications associated with uncontrolled POP. It consisted in a series of steps to be followed by surgeon and medical staff related with surgical patients. Involved interventions during preoperative evaluation, post anesthesia care unit (PACU), and first three postoperative days. This study evaluated the efficacy of a clinical pathway for relieving severe pain in post-operative patients who underwent orthopedic, abdominal, and thoracic surgeries.

Methods: The intervention involved implementation of educational workshops about multimodal and rescue analgesia for physicians and nurses, as well as implementation of measures to monitor POP and analgesia side effects. Two different groups of patients were assessed at 24 hours after surgery using a Verbal Numeric Scale (VNS) for pain intensity. 112 patients were interviewed before the clinical pathway was instituted (Group 1) and 110 patients after its implementation (Group 2). The main outcome was the frequency of severe POP, measured with VNS. Secondary outcomes were Quality of Recovery (QoR) and side effects such as nausea, vomiting, and epigastric pain.

Results: This work showed a statistically significant decrease in severe POP frequency $(\mathrm{p}=0.003)$ and QoR improvement in Group 2 compared to Group 1 (mean: $61.5 \pm 5.0$ vs $59.7 \pm 5.4, \mathrm{p}=0.01$ ). No significant differences in side effects or respiratory depression were observed in either group.
\end{abstract}

Conclusion: This study demonstrates that implementation of a clinical pathway can bring benefits to patients with POP.

Keywords: Critical pathways, pain, postoperative, acute pain, patient care team, pharmacologic actions, pain clinics

\section{Introduction}

Severe Post-Operative Pain (POP) is an issue of high impact worldwide. Prior authors report frequencies of moderateto-severe POP in $41 \%$ of patients; from this percentage, only $23 \%$ patients experience pain relief after receiving treatment [1]. The frequency of POP has reached up to $60 \%$ in several studies conducted in different hospitals [2-5]. In Colombia, a POP prevalence up to $69 \%$ (with different levels of severity in a university hospital in Medellin) [6] was observed.

Evidence has shown that improper relief of POP has harmful physiological and psychological consequences for patients [7-9], increases morbidity, mortality and re-admission for pain management, extends hospitalization, and delays patients return to their normal activities, with resulting increase in costs.

For optimum management of POP in patients, it is not sufficient to simply measure pain unidimensional scales such as VAS or NRS [10]. Currently, there are instruments approved for evaluating Quality of Recovery (QoR), as well as Quality Improvement (QI), and Health Related Quality of Life (SF-36).
Such instruments collect information about the physical and mental function of patients, as well as side effects of the medication and sleep quality, among other variables [11-13].

There is a growing interest in optimizing POP analgesia, because despite a better understanding of pain physiopathology, development of clinical guides and consensus [14], availability of efficient drugs [15], and technological advances, a major impact on the incidence of this problem has not yet been achieved [16].

The clinical pathway for pain management consist of an assistance plan applied sequentially to patients with predictable symptoms such as POP, and involves all professionals who take care of patients and can have an influence on the given outcome. It includes prescription of opioids around the clock to POP patients who are not receiving regional, neuroaxial or patient controlled analgesia, introduce the systematic use of rescue analgesia with opioids, adjuvant analgesics, and prophylaxis of adverse effects associated with analgesia such as nausea or vomiting. Additionally educate medical team 
about monitoring and safety of patients during its execution. That has shown positive results for pain relief $[17,18]$ and for other important aspects such as time spent in a hospital and early rehabilitation [19]. It involves an assistance plan applied to diseases of foreseeable clinical course and involves all professionals who take care of patients and can have an influence on the given outcome $[\mathbf{2 0}, \mathbf{2 1}]$. The clinical pathway puts forth practices and treatments based on the best evidence available and requires consensus among different disciplines during its design and execution.

This study was designed to evaluate the efficacy of a clinical pathway on both severe POP and the QoR of patients undergoing orthopedic, abdominal, and thoracic surgery of a university hospital in Colombia, South America.

\section{Materials and methods Patients}

An intervention clinical study was conducted in POP patients, in order to evaluate the efficacy of a clinical pathway for relieving acute POP in a university hospital of Medellin (Colombia), after approval by the institutional ethics committee. All patients who met the inclusion criteria signed an informed consent for their participation in the study. Group 1, was done before the application of the clinical pathway. This group received traditional management with analgesics prescribed regularly by the surgeon, mainly dypirone and less frequently tramadol [6]. POP evaluation was done without any educative action or pathway.

Group 2 was done in a different set of patients evaluated 4 months after application of clinical pathway for POP, with new recommendations about opioid prescription and educative interventions.

Inclusion criteria for both groups were patients older than 18 years, undergoing orthopedic, abdominal or thoracic emergency or elective surgery. Exclusion criteria were obstetric patients, psychiatric disorders, and acute change in mental status, drug addiction or patients who received regional, neuroaxial or patient controlled analgesia.

A sample size of 112 patients was defined for Group 1 of the study, before implementing the clinical pathway from April $1^{\text {st }}$ to April $30^{\text {thn }}$ of 2008 . And a sample of 110 patients in Group 2 exposed to the clinical pathway from August $1^{\text {st }}$ to August $30^{\text {th }}$ " of 2008, after an appropriate period for the learning of professionals participating in the clinical pathway, surgeons, anesthesiologists, and nurses. POP was assessed at 24 hours after surgery (postoperative day \# 1), using a verbal numeric scale in each group. After implementing the clinical pathway for POP management, a relief of severe POP of at least $10 \%$ assessed at 24 hours postoperatively was considered significant with a Relative Risk (RR) of $0.4,95 \%$ confidence, and $80 \%$ power.

The sample size was calculated using Epilnfo version 6.04 (Centers for Disease Control and Prevention, Atlanta, GA, USA), it was based on the POP frequency of prior studies that reported prevalence of acute POP from $25 \%$ to $45 \%[1,4]$. Questionnaires were conducted by a trained nurse not associated to the project.

\section{Questionnaire}

Questionnaire (Appendix 1) consists of three parts:

1. Measurement of pain through a Verbal Numeric Scale (VNS) for POP on movement and POP at rest.

2. Identification of frequent side effects associated with analgesic management: nausea, vomiting, and epigastric pain.

3. Measurement of Quality of Recovery (QoR Instrument). The QoR instrument has been validated in Colombian spanish $[11,22]$ and consists of a questionnaire intended to determine wellbeing and physical and mental functions of patients with POP. A score higher than or equal to 56 is considered a good QoR.

\section{Clinical pathway principles}

Interventions taught for the implementation of the clinical pathway were as follows: Systematic evaluation of pain and its documentation, opioids as the first-line POP intravenous analgesia, rescue opioid analgesia, multimodal analgesia, evaluation of side effects, and monitoring for alarm signs. A project coordinating nurse was designated for implementation and monitoring of the clinical pathway. During a 4-month period, 25 workshops were given for nursing staff and 12 workshops were given for surgeons and anesthesiologists involved in surgical procedures. Regular visits were made to operating rooms and inpatient rooms to monitor the execution of clinical pathway actions and to correct aspects found to be insufficient.

\section{Clinical pathway guide}

The clinical pathway of POP contains a matrix (Appendix 2) that orients physicians and nurses about procedures, treatments, and monitoring of patients which begins upon admission to the surgery service and is considered finished on post-operative day 3 . This matrix includes a model of multimodal analgesia starting in the recovery phase, rescue analgesia, prophylaxis for adverse effects, a sedation scale, and alert signs for monitoring patients, as included in the clinical pathway. These principles were based on the best evidence available and were published in a pocket manual as reference material for the healthcare team involved in the clinical pathway [23]. Nursing actions during the clinical pathway were monitored through a follow-up form (Appendix 3 ).

\section{Statistical analysis}

A Mann-Whitney $U$ test was employed to analyze the pain VNS, as well as to compare both assessed groups. Median and interquartile range (IQR) was presented. QoR score was presented using median \pm Standard Deviation (SD), significance of $p=0.05$ was defined as the cut-off point. A tendency chi square analysis was performed to determine differences in 
Cadavid-Puentes et al. Journal of Anesthesiology and Clinical Science 2013, http://www.hoajonline.com/journals/pdf/2049-9752-2-31.pdf

both groups with respect to severe pain, moderate pain, and adverse effects such as nausea, vomiting and epigastric pain.

\section{Results}

Demographic variables of the population assessed in both groups are shown in (Table 1). No statistically significant differences in age, sex or type of surgery were observed in the groups ( $p>0.05)$.

By implementing the clinical pathway for POP management a significant decrease of severe pain assessed at 24 hours postoperatively, both at rest and with movement was observed between groups. The frequency of severe pain at rest was $22.3 \%$ and $11.8 \%$ in groups 1 and 2, respectively (Table 2).

Table 1. Demographic variables and distribution of patients by type of surgery.

\begin{tabular}{lll}
\hline Variable & $\begin{array}{l}\text { Group 1 } \\
\mathbf{n}=\mathbf{1 1 2}(\%)\end{array}$ & $\begin{array}{l}\text { Group 2 } \\
\mathbf{n}=\mathbf{1 1 0}(\%)\end{array}$ \\
\hline Sex $^{\star}$ & $39(34.8)$ & $71(64.6)$ \\
\hline Female & $73(65.2)$ & $39(35.5)$ \\
Male & $42.6( \pm 18.9)$ & $40.4( \pm 17.5)$ \\
Age, years & & \\
\hline Type of surgery & & $56(50.9)$ \\
\hline Orthopedic & $51(45.6)$ & $54(49.1)$ \\
\hline Abdominal or thoracic & $61(54.4)$ & \\
\hline
\end{tabular}

${ }^{*} \mathrm{p}>0.05$ for studied variables.

demographic variables of the population assessed in both groups.

Table 2. Post-Operative Pain (POP) Intensity at 24 hours.

\begin{tabular}{lcl}
\hline Type of Pain & $\begin{array}{l}\text { Group 1 } \\
\mathbf{n}=\mathbf{1 1 2}(\%)\end{array}$ & $\begin{array}{l}\text { Group 2 } \\
\mathbf{n}=\mathbf{1 1 0}(\%)\end{array}$ \\
\hline \multicolumn{3}{c}{ At Rest } \\
\hline Absence & $23(20.5)$ & $32(29.1)$ \\
Mild & $29(25.9)$ & $44(40)$ \\
Soderate & $35(31.3)$ & $21(19.1)$ \\
VNS Median (IQR) & $4(4.3)$ & $2(4.0)^{*}$ \\
\hline \multicolumn{4}{c}{ On Movement } \\
\hline Absence & $12(10.7)$ & $2(1.8)$ \\
Mild & $15(13.5)$ & $22(20)$ \\
Moderate & $31(27.6)$ & $60(54.5)$ \\
Severe & $54(48.2)$ & $26(23.6)^{\dagger}$ \\
VNS Median (IQR) & $6.0(4.3)$ & $5.0(2.0)^{\ddagger}$ \\
\hline
\end{tabular}

${ }^{*} \mathrm{p}=0.001 ; \dagger \mathrm{p}=0.0002 ; \neq \mathrm{p}=0.02$

VNS: Verbal Numeric Scale. IQR: Interquartile range.

Mild pain: 1-3, moderate pain: 4-6, severe pain: 7-10.

POP intensity at 24 hours by VNS on movement and at rest, in both groups.
A significant decrease of the mean pain score at rest of 4 $(\mathrm{IQR}=4.3)$ to $2.0(\mathrm{IQR}=4.0)(\mathrm{p}=0.003)$ was observed in groups 1 and 2 .

The frequency of severe pain on movement was $48.2 \%$ and $23.6 \%$ in groups 1 and 2, respectively. A significant decrease of pain on movement was observed in groups 1 and 2 , with means of $6.0(\mathrm{IQR}=4.3)$ and $5.0(\mathrm{IQR}=2.0)(\mathrm{p}=0.0002)$, respectively (Figure 1 ).

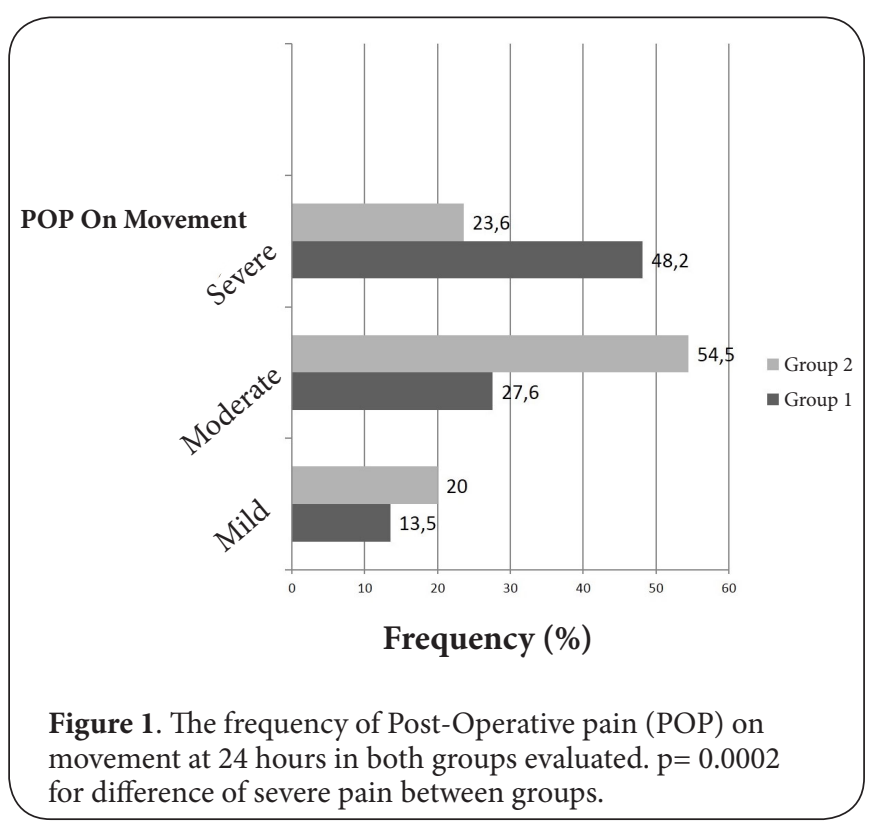

A higher QoR score was found in Group 2 when compared to Group 1 (mean: $61.5 \pm 5.0$ vs 59.7 $\pm 5.4, p=0.01$ ). An association between intensity of pain (POP on movement and POP at rest) and reduction of QoR was observed in both groups (Table 3 ).

No statistically significant differences in frequency of adverse effects between groups were found, including nausea, vomiting, and epigastric pain (Table 4). No major complications such as respiratory depression or hemodynamic instability associated

Table 4. Frequency of Adverse Effects Associated to Analgesia.

\begin{tabular}{llll}
\hline Adverse Effect & $\begin{array}{l}\text { Group 1 } \\
\mathbf{n}=\mathbf{1 1 2}(\mathbf{\%})\end{array}$ & $\begin{array}{l}\text { Group 2 } \\
\mathbf{n}=\mathbf{1 1 0}(\%)\end{array}$ & $\boldsymbol{P}$ \\
\hline Nausea & $28(25)$ & $30(27.2)$ & 0.70 \\
Vomiting & -- & -- & 0.89 \\
Once & $4(3.6)$ & $6(5.5)$ & -- \\
Twice & $2(1.8)$ & $6(5.5)$ & -- \\
Three or more times & $9(8)$ & $6(5.5)$ & -- \\
Epigastric Pain & $19(17)$ & $24(21.8)$ & 0.36 \\
\hline
\end{tabular}

The frequency of adverse effects associated to analgesia in both groups evaluated. 
Cadavid-Puentes et al. Journal of Anesthesiology and Clinical Science 2013,

http://www.hoajonline.com/journals/pdf/2049-9752-2-31.pdf

doi: $10.7243 / 2049-9752-2-31$

Table 3. Variations of QoR with pain intensity at 24 post-operative hours in both groups.

\begin{tabular}{|c|c|c|c|c|c|c|c|c|c|c|}
\hline \multirow[t]{2}{*}{ Pain Intensity (VNS) } & \multicolumn{2}{|c|}{$\mathbf{n}$} & \multicolumn{2}{|c|}{ QoR (mean) } & \multicolumn{2}{|c|}{ Range } & \multicolumn{2}{|c|}{ Standard Deviation } & \multicolumn{2}{|c|}{ Standard Error } \\
\hline & G1 & G2 & G1 & G2 & G1 & G2 & G1 & G2 & G1 & G2 \\
\hline \multicolumn{11}{|c|}{ POP on Movement } \\
\hline Mild & 27 & 22 & 62.00 & 63.06 & $52-69$ & $52-69$ & 4.41 & 4.17 & 0.85 & 1.26 \\
\hline Moderate & 31 & 60 & 58.32 & 62.39 & $49-68$ & $53-68$ & 5.30 & 4.22 & 0.95 & 0.93 \\
\hline Severe & 54 & 26 & 59.5 & 56.77 & $44-67$ & $47-67$ & 5.67 & 6.73 & 0.77 & 3.06 \\
\hline \multicolumn{11}{|c|}{ POP at Rest } \\
\hline Mild & 52 & 44 & 61.3 & 63.46 & $50-69$ & $46-68$ & 4.8 & 3.6 & 0.67 & 1.01 \\
\hline Moderate & 35 & 21 & 58.62 & 60.92 & $49-67$ & $52-66$ & 5.15 & 3.56 & 0.87 & 1.39 \\
\hline Severe & 25 & 13 & 58.36 & 58.58 & $44-67$ & $47-66$ & 6.33 & 7.72 & 1.26 & 3.34 \\
\hline
\end{tabular}

VNS: Verbal Numeric Scale. Mild pain: 1-3, moderate pain: 4-6, severe pain: 7 -10.

QoR: Qualify of Recovery, G1: Group 1, G2: Group 2, POP: Post-Operative Pain.

Variations of QoR with POP intensity at 24 hours by VNS, on movement and at rest, before and after

application of clinical pathway.

with the application of clinical pathway were reported.

\section{Discussion}

The high frequency of severe POP in our study (Group 1) is similar to that described in several hospitals from countries with different levels of development [2-5]. This study was conducted with the purpose of assessing results of a clinical pathway applicable to most patients undergoing surgery, seeking to reduce the frequency of severe POP. The most important result is a statistically significant relief of severe pain on movement of $48 \%$ to $23 \%$. This is relevant because the clinical pathway, as a systematic intervention available for all postoperative patients, brings benefits such as a better post-operative rehabilitation of patients, reduction in morbidity and suffering associated with poor analgesic

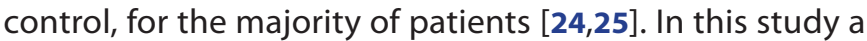
significant reduction in severe POP at rest was also observed; however, the reduction in pain on movement may be more relevant considering that this kind of pain is associated with limitation in early ambulation and self-care.

Initiatives to implement a clinical pathway to control postoperative pain have previously been described in the literature $[17,26]$, with results comparable to those of this study. The emergence of new analgesic techniques, the possibility of titration, and the availability of new drugs $[15,27,28]$ result in the need for a periodic update. It was observed that the use of simple and timely measures, available for all the healthcare staff involved in the management of post-operative patients, promotes acceptable control of POP and improves the quality of patient recovery.

The QoR outcome is considered an objective measure of the consequences of POP in patients [10]. In this study, a better score on the QoR was observed in those patients who had better control of POP when the clinical pathway was implemented. Likewise, prior studies where a new clinical pathway was implemented in surgical models have shown improvement in QoR or similar outcomes [29-31].

These findings confirm the need to establish measures for POP control for all patients undergoing surgical procedures. The literature describes how an educational program for all medical staff taking care of surgical patients and the promotion of systematic pharmacological measures for POP control result in relief of severe pain on movement [32,33].

It should be noted that in our study, although the frequency of severe pain was reduced in a statistically significant manner, this was not the case for moderate pain. Moderate pain continued and was even more frequent in Group 2. We could attribute this finding to various reasons. First, multimodal analgesia can reduce severe pain but if opioids are not administered at adequate doses, this population, which initially suffers from severe pain, will continue experiencing moderate pain. Second, in our institution tramadol is preferred as rescue analgesia instead of strong opioids, which is associated with insufficient analgesia at usual doses [34].

The balance between analgesia and adverse effects is the goal of treatment and truly promotes the patient's post-operative rehabilitation. The adverse effects (nausea, vomiting, epigastric pain) had no statistically significant differences between Groups 1 and 2. Constipation was not assessed in our study since questionnaire was done only at postoperative day \# 1 , and this adverse effect associated with opioids usually takes more than 24 hours to be manifested. Major complications such as respiratory depression or the need to revert patients with Naloxone were not observed; nor 
was a reduction in QoR observed. In contrast, other studies in which clinical pathways have been applied have reported a significant decrease in frequency of adverse effects associated with medication [35]. However, although those studies were directed at a certain type of surgery and included a regional block, which may explain the decreased of consumption of opioids. Even though we had predominantly female patients in group 2, this difference did not seem to change the reduction observed in severe POP frequency after the application of the clinical pathway. It has been described that female patients report higher levels of POP after a surgical stimulus [36].

When analyzing the reasons for which POP treatment is still poor (despite the emergence of new post-surgical pain management guidelines based on the best evidence) $[14,27]$, certain factors such as inadequate education of medical and nursing staff and the lack of institutional policies for offering minimum alternatives of treatment such as rescue analgesia have been identified. Another important element is individual variation in the response to analgesic treatment, which depends on genetic factors, pre-operative anxiety, opioid dependence, sex, among others [36,37].

This intervention to reduce acute POP through a clinical pathway is a first step in a continuous improvement process for management of POP patients; it seeks to achieve a higher coverage of post-operative patients in local hospitals, but it is not designed to replace specialized pain control techniques in major surgeries.

\section{Conclusions}

Severe post-surgical pain of patients in a university hospital in South America is high and comparable to statistics worldwide. Here, it has been demonstrated that simple techniques, multimodal and rescue analgesia in POP management, integrated in a clinical pathway, can be very effective and have low morbidity, provided that they are associated with adequate team education. This finding provides hope for making progress in POP control, as long as administrative will and continuous improvement processes are available.

\section{List of abbreviations}

POP: Post-Operative Pain

QoR: Quality of Recovery

QI: Quality Improvement

RR: Relative Risk

VNS: Verbal Numeric Scale

IQR: Interquartile Range

SD: Standard Deviation

Additional files

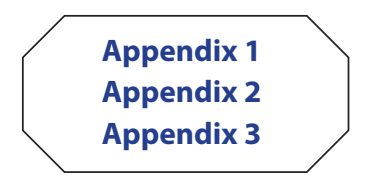

Competing interests

The authors declare that they have no competing interests.

\section{Authors' contributions}

\begin{tabular}{|l|c|c|c|c|c|c|c|c|}
\hline Authors' contributions & AMC & JSG & JMM & MIB & NDG & AMV & DCA & FID \\
\hline $\begin{array}{l}\text { Research concept and } \\
\text { design }\end{array}$ & $\checkmark$ & -- & -- & -- & -- & -- & -- & -- \\
\hline $\begin{array}{l}\text { Collection and/or } \\
\text { assembly of data }\end{array}$ & -- & -- & $\checkmark$ & -- & -- & $\checkmark$ & -- & $\checkmark$ \\
\hline $\begin{array}{l}\text { Data analysis and } \\
\text { interpretation }\end{array}$ & $\checkmark$ & $\checkmark$ & $\checkmark$ & $\checkmark$ & $\checkmark$ & $\checkmark$ & $\checkmark$ & -- \\
\hline Writing the article & $\checkmark$ & $\checkmark$ & -- & $\checkmark$ & $\checkmark$ & -- & -- & -- \\
\hline $\begin{array}{l}\text { Critical revision of the } \\
\text { article }\end{array}$ & $\checkmark$ & $\checkmark$ & -- & $\checkmark$ & $\checkmark$ & -- & $\checkmark$ & -- \\
\hline Final approval of article & $\checkmark$ & $\checkmark$ & -- & -- & -- & -- & -- & -- \\
\hline Statistical analysis & $\checkmark$ & $\checkmark$ & -- & -- & -- & -- & $\checkmark$ & -- \\
\hline
\end{tabular}

Acknowledgement and funding

This study was funded by an educational grant from International Association for the Study of Pain (education in pain for developing countries). We thank to Hospital Universitario San Vicente Fundacion for its unrestricted help in allowing workshops with surgical team and collection data with patients.

Publication history

EIC: D. John Doyle, Case Western Reserve University, USA. Received: 05-Jun-2013 Revised: 26-Nov-2013

Accepted: 05-Dec-2013 Published: 20-Dec-2013

\section{References}

1. Dolin SJ, Cashman JN and Bland JM. Effectiveness of acute postoperative pain management: I. Evidence from published data. Br J Anaesth. 2002; 89:409-23. I Article I PubMed

2. Sommer M, de Rijke JM, van Kleef M, Kessels AG, Peters ML, Geurts JW, Gramke HF and Marcus MA. The prevalence of postoperative pain in a sample of 1490 surgical inpatients. Eur J Anaesthesiol. 2008; 25:267-74. | Article | PubMed

3. Visentin M, Zanolin E, Trentin L, Sartori S and de Marco R. Prevalence and treatment of pain in adults admitted to Italian hospitals. Eur J Pain. 2005; 9:61-7. | Article | PubMed

4. Rocchi A, Chung F and Forte L. Canadian survey of postsurgical pain and pain medication experiences. Can J Anaesth. 2002; 49:1053-6. | Article I PubMed

5. Gallego JI, Rodríguez MR, Vázquez JC and Gil M. Estimación de la prevalencia e intensidad del dolor postoperatorio y su relación con la satisfacción de los pacientes. Rev Soc Esp Dolor. 2004; 11:197-202.

6. Cardona EF, Castaño ML and Builes AM. Manejo del dolor posquirúrgico en el Hospital Universitario San Vicente de Paúl de Medellín. Rev Col Anest. 2003; 31:111-7.

7. Joshi GP and Ogunnaike BO. Consequences of inadequate postoperative pain relief and chronic persistent postoperative pain. Anesthesiol Clin North America. 2005; 23:21-36. | Article I PubMed

8. Vásquez JM and Torres LM. Prevalencia del dolor postoperatorio. Alteraciones fisiopatológicas y sus repercusiones. Rev Soc Esp Dolor. 2000; 7:465-76. | Pdf

9. Apfelbaum JL, Chen C, Mehta SS and Gan TJ. Postoperative pain experience: results from a national survey suggest postoperative pain continues to be undermanaged. Anesth Analg. 2003; 97:534-40. | Article I PubMed

10. Wu CL and Richman JM. Postoperative pain and quality of recovery. Curr Opin Anaesthesiol. 2004; 17:455-60. I Article I PubMed

11. Myles PS, Weitkamp B, Jones K, Melick J and Hensen S. Validity and reliability of a postoperative quality of recovery score: the QoR40. Br J Anaesth. 2000; 84:11-5. | Article 
12. Gracely RH. Pain measurement. Acta Anaesthesiol Scand. 1999; 43:897908. | Article | PubMed

13. Quality improvement guidelines for the treatment of acute pain and cancer pain. American Pain Society Quality of Care Committee. JAMA. 1995; 274:1874-80. | Article | PubMed

14. Practice guidelines for acute pain management in the perioperative setting: an updated report by the American Society of Anesthesiologists Task Force on Acute Pain Management. Anesthesiology. 2012; 116:24873. | Article | PubMed

15. Aubrun F, Mazoit JX and Riou B. Postoperative intravenous morphine titration. Br J Anaesth. 2012; 108:193-201. | Article | PubMed

16. White $\mathrm{PF}$ and Kehlet $\mathrm{H}$. Improving postoperative pain management: what are the unresolved issues? Anesthesiology. 2010; 112:220-5. | Article | PubMed

17. Dufault MA and Willey-Lessne C. Using a collaborative research utilization model to develop and test the effects of clinical pathways for pain management. J Nurs Care Qual. 1999; 13:19-33. | Article | PubMed

18. Ayalon O, Liu S, Flics S, Cahill J, Juliano K and Cornell CN. A Multimodal Clinical Pathway Can Reduce Length of Stay After Total Knee Arthroplasty. HSS J. 2011; 7:9-15. | Article

19. Rotter T, Kinsman L, James E, Machotta A, Gothe H, Willis J, Snow P and Kugler J. Clinical pathways: effects on professional practice, patient outcomes, length of stay and hospital costs. Cochrane Database Syst Rev. 2010; CD006632. | Article | PubMed

20. Campbell H, Hotchkiss R, Bradshaw N and Porteous M. Integrated care pathways. BMJ. 1998; 316:133-7. | Article | PubMed Abstract | PubMed Full Text

21. Grimshaw J, Freemantle N, Wallace S, Russell I, Hurwitz B, Watt I, Long $A$ and Sheldon T. Developing and implementing clinical practice guidelines. Qual Health Care. 1995; 4:55-64. | Article | PubMed Abstract I PubMed Full Text

22. Eslava-Schmalbach J, Gaitán-Duarte H and Gómez-Restrepo C. Escala para medir la calidad de la recuperación postanestésica desde la perspectiva del usuario. Rev Salud Publica (Bogota). 2006; 8:52-62. I Article

23. Cadavid AM, Berrío M, Gómez N and Mendoza JM. Manual de Analgesia Postoperatoria Básica. Medellín: Artes y Letras. 2007; 9-20. | Pdf

24. Cohen MJ and Schecter WP. Perioperative pain control: a strategy for management. Surg Clin North Am. 2005; 85:1243-57. | Article | PubMed

25. Lohman $D$, Schleifer $R$ and Amon JJ. Access to pain treatment as a human right. BMC Med. 2010; 8:8.| Article

26. Elshamy K and Ramzy E. The Effect of Postoperative Pain Assessment and Management Monitoring Program on Surgical Nurses' Documentation, Knowledge, Attitudes, and Patients' Satisfaction at Mansoura University Hospitals. J Am Sci. 2011; 7:373-87. | Pdf

27. Wu CL and Raja SN. Treatment of acute postoperative pain. Lancet. 2011; 377:2215-25. | Article | PubMed

28. Tzortzopoulou A, McNicol ED, Cepeda MS, Francia MB, Farhat T and Schumann R. Single dose intravenous propacetamol or intravenous paracetamol for postoperative pain. Cochrane Database Syst Rev. 2011; 5:1-28. | Article | PubMed

29. Broder MS and Bovone S. Improving treatment outcomes with a clinical pathway for hysterectomy and myomectomy. J Reprod Med. 2002; 47:999-1003. | Article | PubMed

30. Pennington JM, Jones DP and McIntyre S. Clinical pathways in total knee arthroplasty: a New Zealand experience. J Orthop Surg (Hong Kong). 2003; 11:166-73. | Pdf | PubMed

31. Lemmens L, van Zelm R, Vanhaecht $K$ and Kerkkamp H. Systematic review: indicators to evaluate effectiveness of clinical pathways for gastrointestinal surgery. J Eval Clin Pract. 2008; 14:880-7. | Article | PubMed

32. Harmer M and Davies KA. The effect of education, assessment and a standardised prescription on postoperative pain management. The value of clinical audit in the establishment of acute pain services. Anaesthesia. 1998; 53:424-30. | Article | PubMed
33. Karlsten R, Strom K and Gunningberg L. Improving assessment of postoperative pain in surgical wards by education and training. Qual Saf Health Care. 2005; 14:332-5. | Article | PubMed Abstract | PubMed Full Text

34. Thevenin A, Beloeil H, Blanie A, Benhamou D and Mazoit JX. The limited efficacy of tramadol in postoperative patients: a study of ED80 using the continual reassessment method. Anesth Analg. 2008; 106:622-7. | Article I PubMed

35. Hebl JR, Dilger JA, Byer DE, Kopp SL, Stevens SR, Pagnano MW, Hanssen $A D$ and Horlocker TT. A pre-emptive multimodal pathway featuring peripheral nerve block improves perioperative outcomes after major orthopedic surgery. Reg Anesth Pain Med. 2008; 33:510-7. | Article | PubMed

36. Sommer M, de Rijke JM, van Kleef M, Kessels AG, Peters ML, Geurts JW, Patijn J, Gramke HF and Marcus MA. Predictors of acute postoperative pain after elective surgery. Clin J Pain. 2010; 26:87-94. | Article | PubMed

37. Ip HY, Abrishami A, Peng PW, Wong J and Chung F. Predictors of postoperative pain and analgesic consumption: a qualitative systematic review. Anesthesiology. 2009; 111:657-77. | Article | PubMed

\section{Citation:}

Cadavid-Puentes AM, Gonzalez-Avendano JS, Mendoza JM, Berrío MI, Gomez ND, Villalba AM, AguirreAcevedo DC and Diaz FI. Impact of a clinical pathway for relieving severe post-operative pain at a university hospital in South America. J Anesthesiol Clin Sci. 2013; 2:31. http://dx.doi.org/10.7243/2049-9752-2-31 